\title{
AVALIAÇÃO ECONÔMICA DA RECUPERAÇÃO DE ÁREAS MINERADAS NA EMPRESA COPELMI MINERAÇÃO S.A., BUTIÁ, RS, BRASIL
}

\author{
ECONOMICAL EVALUATION OF RENATURING DEGRADED AREAS OF THE COPELMI \\ MINE COMPANY IN BUTIÁ, RS, BRAZIL
}

Peter Spathelf $^{1}$ Irene Seling ${ }^{2}$ Rosito Zepenfeld Borges ${ }^{3}$

\section{- NOTA -}

RESUMO

\begin{abstract}
Com base em um inventário, foram calculados três critérios econômicos (Taxa Interna de Retorno, Valor Presente Líquido e Relação Benefício Custo) para avaliar os resultados econômicos de plantações de acácia-negra, Pinus sp e de uma cobertura de grama para áreas degradadas na Mina de Recreio (COPELMI Mineração S.A.), em Butiá, RS. Como variante, economicamente ótima, foi encontrada a plantação com acácianegra com uma idade de rotação de 5 anos.
\end{abstract}

Palavras-chave: áreas degradadas, Acacia mearnsii, Pinus $s p$, grama, análise econômica.

\section{SUMMARY}

On the base of an inventory three economical criteria (Internal Rate of Return, Net Present Value and Benefit Cost Ratio) were calculated to analyze the economic results of plantations of Acacia mearnsii and Pinus sp and a grass cover on degraded areas in Mina de Recreio (COPELMI Mineração S.A), in Butiá, Rio Grande do Sul, Brazil. The plantation of Acacia mearnsii with a rotation age of 5 years was found as the economically optimal variant.

Key words: degraded areas, Acacia mearnsii, Pinus sp, grass, economic analysis.

em um entendimento entre a COPELMI
MINERAÇÃO S. A. e o Centro de Pesquisas Florestais (CEPEF), a fim de avaliar as possibilidades do manejo sustentável das áreas reflorestadas na área da Mina do Recreio, localizada no município de Butiá, Rio Grande do Sul. A maior parte da área recuperada da mina é coberta com grama (313,1 hectares). Um plantio de 129,4 hectares de floresta foi realizado em 1994. A floresta, no momento de levantamento de dados, contava com 6 anos de idade. Mais 20 hectares foram plantados em 1997 e 18 hectares em 1998. Os reflorestamentos constituem-se de povoamentos de Acacia mearnsii (acácia-negra), e o levantamento dos dados foi feito em julho de 1999.

O estudo teve os seguintes objetivos: 1) avaliar quantitativamente os povoamentos amostrados; 2) avaliar o rendimento econômico a longo prazo e alternativas de cobertura do solo.

Os plantios foram realizados com 3.333 plantas por hectare. O inventário usado foi o de uma ocasião, implantado mediante o método de amostragem sistemática. Assumindo um coeficiente de variação entre 25 e $30 \%$, obteve-se uma intensidade de amostragem de 30 parcelas para o talhão principal (5 anos). Portanto, amostrou-se 0,93\% da área total das plantações com a idade de 5

\footnotetext{
${ }^{1}$ Engenheiro Florestal, Doutor, Programa de intercâmbio DAAD/CAPES. Universidade Federal de Santa Maria (UFSM). Centro de Ciências Rurais (CCR), Departamento de Ciências Florestais, (DCF), 97105-900, Santa Maria, RS. E-mail: peter.spathelf@fdtue.bwl.de. Endereço para correspondência: Kleegasse 6, 72108 Rottenburg, Alemanha.

${ }^{2}$ Engenheiro Florestal, Doutora, Professora Visitante, CCR, DCF, UFSM.

${ }^{3}$ Acadêmico, Curso de Engenharia Florestal, CCR, DCF, UFSM.
} 
anos. As equações para a determinação do volume das árvores inventariadas foram desenvolvidas pela empresa SETA, localizada no município de Estância Velha, RS. Para obter o peso da casca verde, usou-se a equação de SCHNEIDER (1978). Com a altura dominante nas parcelas amostrais na idade de medição, obteve-se o índice de sítio (SCHNEIDER \& SILVA, 1980).

Assim estimou-se o desenvolvimento dos povoamentos até o final da rotação e obteve-se o volume médio sem casca $\left(\mathrm{m}^{3} / \mathrm{ha}\right)$ e o peso da casca verde $(\mathrm{kg} / \mathrm{ha})$ numa idade de 6,7 e 8 anos.

Para avaliações econômicas de sistemas de produção, foram usados diferentes critérios de determinação a fim de estabelecer um "ranking" nos métodos propostos: 1) Valor Presente Líquido (VPL); 2) Taxa Interna de Retorno (TIR); e 3) Relação Benefício/Custo (RBC).

Empregando tais critérios de decisão, avaliou-se o sucesso econômico dos povoamentos de acácia-negra com rotações de 6,7 e 8 anos, considerando corte raso ao final da rotação. Foi levado em conta a comercialização da madeira (lenha) e da casca verde dos povoamentos. Como variante de comparação foi considerada a recuperação da área com Pinus sp ou com gramíneas (exigência mínima legal). Os coeficientes técnicos e os preços/custos são sumarizados nas tabelas $1-3$

Tabela 1 - Custos e preços na avaliação econômica para acácianegra.

\begin{tabular}{lcc}
\hline & Medida & Valor \\
\hline Custos & Plantio & $720,00 \mathrm{R} \$ / \mathrm{ha}$ \\
& $(3333$ mudas/ha) & \\
& Combate à formiga & $38,40 \mathrm{R} \$ / \mathrm{ha}$ \\
& (somente no $1^{0}$ ano) & \\
& Valor da terra & $600,00 \mathrm{R} \$ / \mathrm{ha}$ \\
& Administração e manutenção & $45,00 \mathrm{R} \$ / \mathrm{ha} /$ ano \\
Preços & Madeira comercial (venda em pé) & $9,50 \mathrm{R} \$ /$ st. \\
& Casca verde na floresta & $52,15 \mathrm{R} \$ /$ tonelada \\
\hline
\end{tabular}

Tabela 2 - Custos e preços na avaliação econômica para Pinus sp.

\begin{tabular}{lcc}
\hline & Medida & Valor \\
\hline \multirow{2}{*}{ Custos } & Plantio (2500 mudas/ha) & $600,00 \mathrm{R} \$ / \mathrm{ha}$ \\
& Manutenção (no $2^{0}$ ano) & $50,00 \mathrm{R} \$ / \mathrm{ha}$ \\
& Valor de terra & $600,00 \mathrm{R} \$ / \mathrm{ha}$ \\
\multirow{2}{*}{ Preço } & Administração e manutenção & $45,00 \mathrm{R} \$ \mathrm{ha} / \mathrm{ano}$ \\
& Madeira comercial (venda em pé) & $7,00 \mathrm{R} \$ / \mathrm{st}$. \\
\hline
\end{tabular}

Tabela 3 - Custos na avaliação econômica para grama.

\begin{tabular}{lcc}
\hline & Medida & Valor \\
\hline Custos & Semeadura & $1.200,00 \mathrm{R} \$ / \mathrm{ha}$ \\
& Valor de terra & $600,00 \mathrm{R} \$ / \mathrm{ha}$ \\
& Administração e manutenção & $45,00 \mathrm{R} \$ \mathrm{ha} / \mathrm{ano}$ \\
\hline
\end{tabular}

O volume do povoamento na idade 5 refere-se ao inventário. Por causa da ausência e morte de árvores nos povoamentos (grau de estoqueamento real ca. 0,75), duas variantes na análise econômica para acácia-negra foram calculadas: uma com um grau de estoqueamento (GE) de 0,75 e uma com um grau de estoqueamento de 1, isto é, uma alternativa mais otimista (Tabelas 4 e 5).

A tabela 6 evidencia os resultados econômicos, supondo uma cobertura com acácianegra. O Valor Presente Líquido e a Relação Benefício/Custo foram calculados com quatro diferentes taxas de juros $(6,8,10$ e $12 \%)$.

Também uma variante com o gênero Pinus sp foi calculada. Foi assumida uma idade de rotação de 15 anos e um desbaste na idade de 10 anos (tabela de produção de SCHNEIDER \& OESTEN, 1999). Supondo os dados fornecidos na tabela 2, um rendimento madeireiro calculado de $803,60 \mathrm{R} \$$ /ha no desbaste e de $1547,70 \mathrm{R} \$$ /ha no corte final foram o ponto de partida para a análise (Tabela 7). Também, o Valor Presente Líquido e a Relação Benefício/Custo foram calculados com quatro diferentes taxas de juros $(6,8,10$ e 12\%).

O valor de recuperação com gramíneas é de, aproximadamente, 1.200,00R $\$ /$ ha. Essa cobertura não permite receitas após um período determinado, mas somente resultam despesas no início da recuperação.

Tanto as Taxas Internas de Retorno como os Valores Presentes Líquidos mostram que a variante de recuperação das áreas com acácia-negra apresenta os melhores resultados. $\mathrm{O}$ modelo de recuperação com a conífera Pinus sp mostra

Tabela 4 - Casca verde (cv) e volume de madeira com casca (Vcc) e sem-casca (Vsc) para acácia-negra $(\mathrm{GE}=$ $0,75)$.

\begin{tabular}{lcccc}
\hline Idade & cv (kg/ha) & V cc $\left(\mathrm{m}^{3}\right)$ & $\mathrm{Vsc}\left(\mathrm{m}^{3}\right)$ & $\mathrm{Vsc}(\mathrm{st})$. \\
\hline 5 & 14.447 & 86,4 & 69,1 & 102,3 \\
6 & 15.756 & 95,1 & 76,1 & 112,6 \\
7 & 17.085 & 104,1 & 83,3 & 123,3 \\
8 & 18.417 & 113,1 & 90,5 & 133,9 \\
\hline
\end{tabular}

Tabela 5 - Casca verde (cv) e volume de madeira com casca $(\mathrm{Vcc})$ e sem-casca $(\mathrm{Vsc})$ para acácia-negra $(\mathrm{GE}=1)$.

\begin{tabular}{lcccc}
\hline Idade & $\mathrm{cv}(\mathrm{kg} / \mathrm{ha})$ & $\mathrm{Vcc}\left(\mathrm{m}^{3}\right)$ & $\mathrm{Vsc}\left(\mathrm{m}^{3}\right)$ & $\mathrm{Vsc}(\mathrm{st})$. \\
\hline 5 & 18.059 & 108,0 & 86,4 & 127,9 \\
6 & 19.695 & 118,9 & 95,1 & 140,7 \\
7 & 21.356 & 130,1 & 104,1 & 154,1 \\
8 & 23.021 & 141,4 & 113,1 & 167,4 \\
\hline
\end{tabular}


Tabela 6 - Taxa Interna de Retorno (TIR), Valor Presente Líquido (VPL) e Relação Benefício/Custo (RBC) na variante de acácia-negra (r = idade de rotação, $\mathrm{GE}$ = grau de estoqueamento); a melhor variante a respeito de cada critério em negrito.

\begin{tabular}{|c|c|c|c|c|c|c|c|c|c|}
\hline $\begin{array}{l}\text { Critério } \\
\text { econômico }\end{array}$ & $\begin{array}{c}\text { Taxa de } \\
\text { juros }(\%)\end{array}$ & $\begin{aligned} \mathrm{r} & =5 \\
\mathrm{GE} & =0,75\end{aligned}$ & $\begin{array}{c}r=5 \\
\mathrm{GE}=1\end{array}$ & $\begin{aligned} \mathrm{r} & =6 \\
\mathrm{GE} & =0,75\end{aligned}$ & $\begin{array}{c}\mathrm{r}=6 \\
\mathrm{GE}=1\end{array}$ & $\begin{aligned} \mathrm{r} & =7 \\
\mathrm{GE} & =0,75\end{aligned}$ & $\begin{array}{c}\mathrm{r}=7 \\
\mathrm{GE}=1\end{array}$ & $\begin{aligned} \mathrm{r} & =8 \\
\mathrm{GE} & =0,75\end{aligned}$ & $\begin{array}{c}r=8 \\
\mathrm{GE}=1\end{array}$ \\
\hline TIR (\%) & & 8,1 & 11,9 & 7,6 & 10,8 & 7,1 & 10 & 6,8 & 9,3 \\
\hline \multirow[t]{4}{*}{ VPL (R\$/ha) } & 6 & 267 & 589 & 254 & 587 & 238 & 581 & 216 & 433 \\
\hline & 8 & 145 & 439 & 104 & 402 & 61 & 362 & 14 & 200 \\
\hline & 10 & 38 & 306 & -25 & 242 & -88 & 177 & 154 & 7 \\
\hline & 12 & -56 & 189 & -136 & 104 & -214 & 19 & -292 & -153 \\
\hline \multirow[t]{4}{*}{$\mathrm{RBC}$} & 6 & 1,26 & 1,58 & 1,23 & 1,54 & 1,21 & 1,51 & 1,18 & 1,36 \\
\hline & 8 & 1,14 & 1,43 & 1,1 & 1,37 & 1,05 & 1,32 & 1,01 & 1,17 \\
\hline & 10 & 1,04 & 1,3 & 0,98 & 1,22 & 0,92 & 1,15 & 0,87 & 1 \\
\hline & 12 & 0,95 & 1,18 & 0,88 & 1,09 & 0,81 & 1,02 & 0,75 & 0,87 \\
\hline
\end{tabular}

Tabela 7 - Taxa Interna de Retorno, Valor Presente Líquido e Relação Benefício/Custo na variante de cobertura vegetal com Pinus sp.

\begin{tabular}{cc}
\hline Critério econômico & Pinus sp \\
\hline $\begin{array}{c}\text { Taxa Interna de Retorno } \\
\text { Valor Presente Líquido (R \$/ha) com uma taxa } \\
\text { de juros de }\end{array}$ & $3,9 \%$ \\
$6 \%$ & -303 \\
$8 \%$ & -534 \\
$10 \%$ & -705 \\
$12 \%$ & -831 \\
$6 \%$ & 0,78 \\
$8 \%$ & 0,62 \\
$10 \%$ & 0,49 \\
$12 \%$ & 0,39 \\
\hline
\end{tabular}

resultados piores em comparação com uma recuperação com acácia-negra. Na variante de grama, há despesas no início para a semeadura e nenhuma receita após. Mas, as despesas inicias são maiores do que nas variantes com acácia-negra ou com Pinus sp. Já por essa única causa, a variante com grama parece desvantajosa do ponto de vista econômico.

A melhor variante é a da acácia-negra de 5 anos de rotação e com um grau de estoqueamento de 1. Estimativas mostram também que, com rotações abaixo de 5 anos, a renda fica abaixo daquela com 6 anos. Quanto ao estoque, os valores revelam que o estoqueamento mais denso possível deveria ser aspirado em conseqüência da produção maior de casca verde e madeira.

Para aumentar as receitas empresariais, o objetivo da empresa deve ser transformar as áreas ainda cobertas com grama em povoamentos de acácia-negra. Essa transformação exige, no começo, um investimento para o plantio, mas tem como expectativa receitas maiores do que com uma recuperação com gramíneas.

\section{REFERÊNCIAS BIBLIOGRÁFICAS}

SCHNEIDER, P.R. Modelo de equação e tabelas para avaliar o peso de casca de acácia-negra, Acacia mearnsii de Wild. Curitiba, 1978. 149p. Dissertação (Mestrado em Engenharia Florestal) - Programa de Pós-graduação em Engenharia Florestal, Universidade Federal do Paraná, 1978.

SCHNEIDER, P.R., SILVA, J.A. da. Índice de sítio para acácianegra. Acacia mearnsii de Wild. Brasil Florestal, Brasília, n.36, p.58-82, 1980.

SCHNEIDER, P.R., OESTEN, G. Tabelas auxiliares para o manejo de Pinus elliottii e Araucaria angustifolia para a região do planalto médio do Rio Grande do Sul. Santa Maria : CEPEF, Universidade Federal de Santa Maria, 1999. $118 \mathrm{p}$.

Ciência Rural, v. 31, n. 5, 2001. 